\title{
Identification of Determinant Factors for Car Accident Levels Occurred in Mekelle City, Tigray, Ethiopia: Ordered Logistic Regression Model Approach.
}

Hagazi Gebre Meles ( $\nabla$ hagazigebre@gmail.com )

Mekelle University https://orcid.org/0000-0001-5773-4011

Desta Brhanu Gebrehiwot

Mekelle University College of Business and Economics

Fireweini Gebrearegay Tela

Mekelle University College of Health Sciences

Gebretsadik Gebru Wubet

Mekelle University College of Natural and Computational Sciences

Teodros Gebregergis

Mekelle University College of Natural and Computational Sciences

Research article

Keywords: Car accident, Ordered Logistic Regression, Injury Level

Posted Date: December 18th, 2019

DOI: https://doi.org/10.21203/rs.2.19228/v1

License: (c) (1) This work is licensed under a Creative Commons Attribution 4.0 International License.

Read Full License 
1 Identification of Determinant Factors for Car Accident Levels Occurred in Mekelle City,

2 Tigray, Ethiopia: Ordered Logistic Regression Model Approach.

3 Hagazi Gebre Meles $^{1 *}$, Desta Brhanu Gebrehiwot ${ }^{2}$, Fireweini Gebrearegay Tela ${ }^{3}$, 4 Gebretsadik Gebru Wubet $^{4}$, Teodros Gebregergis ${ }^{4}$

$5{ }^{1}$ Department of Biostatistics, School of Public Health, College of Health Sciences, Mekelle

6 University, Ethiopia

$7 \quad{ }^{2}$ Department of Economics, College of Business and Economics, Mekelle University, Ethiopia

$8{ }^{3}$ Department of Nutrition and dietetics, School of Public Health, College of Health Sciences,

9 Mekelle University, Ethiopia

$10{ }^{4}$ Deparment of Statistics, College of Natural and Computational Sciences, Mekelle University,

11 Ethiopia

12 HGM: hagazigebre@gmail.com

13 DBG: zdesta2003@ gmail.com

14 FG: gebrearegayfireweini@gmail.com

15 GGW: gebretsadik.gebru@ mu.edu.et

16 TG: tewodros.gg@gmail.com

17

18 * Corresponding Author to Hagazi Gebre Meles

19 Email: hagazigebre@gmail.com

20 Cell Phone: +251916133801 


\section{Abstract}

Background: The car accident injury level is known to be a result of a complex interaction of factors to drivers' behavior, vehicle characteristics and environmental condition. Therefore it is obvious that identifying the contribution of the factors to the accident injury is very critical. The objective of study was to perform descriptive analysis to see the characteristics of car accident, to assess the prevalence and determinants of road safety practices in Mekelle City, Tigray, Ethiopia.

Methods: A random sample of data was extracted from traffic police office from September 2014- July 2017. An ordered logistic regression model was used to examine factors that worsen the car accident level.

Result: A total sample of 385 car accidents were considered in the study of which $56.7 \%$ were fatal, $28.6 \%$ serious and $14.7 \%$ slight injury. The model estimation result showed that, being experienced drivers (Coef. $=0.686$; $\mathrm{p}$-value $<=0.050$ ) were found to increase the level of injury. On the other hand, being private vehicle (Coef. $=-1.160$; $\mathrm{p}$-value $<=0.010$ ), the type of accident of vehicle with pedestrian (Coef. $=-2.852$; p-value $<=0.010$ ), being heavy truck (Coef. $=-0.656$; p-value $<=0.050$ ), being a cross country buss (Coef. $=-0.889$; p-value $<=0.050$ ) and being owner of vehicle is the driver himself (Coef. $=-.690$, p-value $<=0.050$ ) were found to decrease the level of car accident injury severity.

Conclusion: In conclusion, it is better to create continued awareness to those who are experienced drivers, who carelessly follow the traffic rules. Special attention is required to government owned vehicle drivers, as they were found to increase the level of car accident injury through different short term trainings.

Key Words: Car accident, Ordered Logistic Regression, Injury Level

(1)

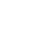

7

8

70




\section{Background}

72 Worldwide, 1.2 million people are killedand up to 50 million injured each year (WHO, 2013). In

732020 , road traffic injuries are projected to become the 3rd largest cause of disabilitiesin the world

74 (Odero \& Ayuku, 2003).

75 Current and projected trends in motorization indicated that the problem of RTAs will get worse,

76 leading to a global public health crisis. It has been indicated that, accordingly, by 2020 traffic

77 accident is expected to be the third major killer after HIV/AIDS and TB (Peden et al., 2004).

78 Transportation is one of the basic necessities for the simple functioning of societies as its

79 demand is greatly related to the movement of people from one place to another. Since every

80 bustle of human being has its own consequences (positive or negative) transport is not an

81 exception to this circumstance. In connotation to Rallis, T., (Rallis, 1977) have stated that the

82 constraints associated with transport include the risk of traffic mobbing, traffic coincidence,

83 pollution, noise, and the like. Road Traffic Accidents (RTAs) are among the most damaging

84 environmental effects, which have caused from transportation development. Road safety,

85 therefore, urges serious concern worldwide.

86 RTAs have turned out to be a huge global public health and development problem killing almost

871.2 million people a year and wounding or disabling about 20-50 million people more; the 88 combined population of five of the world's large cities (Goswami \& Sonowal, 2009). The 89 statistical profile reflects that in 2002, RTAs charged the global community about US \$ 518 90 billion.

91 In similar manner (WHO, 2013) reports that; Road traffic injuries are a major but neglected

92 global public health disruptive, necessitating concerted sweats for actual and sustainable

93 prevention. Of all the systems that people have to pact with on a daily basis, road transport is the 3| P a g e 
94 most composite and the most dangerous. The catastrophe behind these figures regularly attracts

95 less media courtesy than other, less recurrent but more unusual types of tragedy.

\section{Method}

97 A cross sectional study was conducted for secondary data found from Mekelle Zone Trafic

98 Police Office. Accidents are recorded by the traffic police on daily basis. This study was,

99 therefore, based on a secondary data extracted from Mekelle Traffic Control and Investigation

100 Department. The observations were random sample accidents that occurred over the recent three

101 consecutive years (September 2014- July 2017). Mekelle City is located in the northern part of

102 Ethiopia in Tigray National Regional State, Mekelle Zone at a distance of $783 \mathrm{~km}$ from Addis

103 Ababa, Ethiopia.

104 The sample size was calculated using single population proportion formula by taking $20 \%$

105 prevalence of car accident for low income countries (Organization, 2009), for there is no clear

106 prevalence calculated for Mekelle city or for any other Ethiopia region. And with 95\%

107 confidence level for, $4 \%$ desired precision and accounted for one stage sampling, the calculation

108 procedures and the sample size were as follows:

$$
n=\frac{\left(Z_{\alpha / 2}\right)^{2} * P(1-P)}{d^{2}}
$$

Wheren $=$ the required Sample size

$111 \mathrm{Z}=$ the standard score corresponding to $95 \% \mathrm{CI}$, and is equal to 1.96

$112 \mathrm{P}=$ the prevalence of car accident for low income countries $(20 \%)$

$113 d^{2}=$ margin of error which is taken as $4 \%(0.04)$ Using the above formula 


$$
\begin{gathered}
n=\frac{\left(Z_{\propto / 2}\right)^{2} * P(1-P)}{d^{2}} \\
n=\frac{(1.96)^{2} * 0.2(1-0.2)}{(0.04)^{2}}
\end{gathered}
$$

$$
n=384.16 \cong 385
$$

117 Systematic sampling technique was used to select the study participants (accidents recorded).

118 The total registered number of accidents in the office for the three consecutive years (Sept. 2014 119 - Aug. 2017) were 4500, then when we divide to the sample size (385), it became 11.69

120 approximately 12 . Then we randomly select one accident from the total and then continued to 121 select the next $12^{\text {th }}$ record, and then the next $12^{\text {th }}$ record, $\ldots$, then ended up to the determined 122 sample size (385). Data were collected from the daily registration book of the traffic police 123 office. It was extracted by well informed collectors under supervision of the authors. Training 124 was provided to the data collectors for three consecutive days on the purpose of the study, the 125 contents of the extraction sheet prepared by the authors, particularly on issues related to 126 confidentiality of the office.

127 Operational definitions

128 Fatal accident: At least one person (driver, passenger or pedestrian) died, within 30 days, from 129 injuries received as a result of an RTC.

130 Severe Injury: At least one person was injured and admitted in hospital, but no deaths occurred.

131 Slight injury: At least one person required medical care, but no fatalities or injuries that required 132 hospitalization occurred.

133 Property Damages: Collisions which did not result in injuries or deaths.

\section{Objectives of the Study}

$135>$ To explore the nature and incidence of car accident at different levels.

$136>$ To assess the effect of multiple covariates in different levels of car accident. 
To identify the most determinant factors of car accident using Logistic Regression models.

140 We use the Logistic Regression Model (LRM) whenever our response variable is a categorical

141 (qualitative nominal type variable) or in short the response variable is binary or dichotomous

142 furthermore the difference between logistic and linear regressions remains upon both the choice

143 of parametric model and in the assumptions(Al-Ghamdi, 2002). That is after accommodating the 144 differences; the methods applied in an analysis using logistic regression follow the same general 145 principles used in linear regression analysis.

146 But ordered logit model also ordered logistic regression or proportional odds model, is an ordinal 147 regression model — that is, a regression model for ordinal dependent variables(McCullagh, 1980).

148 For example, if one question on a survey is to be answered by a choice among "poor", "fair", 149 "good", and "excellent", and the purpose of the analysis is to see how well that response can be 150 predicted by the responses to other questions, some of which may be quantitative, then ordered 151 logistic regression may be used. It can be thought of as an extension of the logistic regression 152 model that applies to dichotomous dependent variables, allowing for more than two (ordered) 153 response categories.

154 The model only applies to data that meet the proportional odds assumption, the meaning of 155 which can be exemplified as follows. Suppose the proportions of members of the statistical 156 population who would answer "poor", "fair", "good", "very good", and "excellent" are 157 respectively $p_{1}, p_{2}, p_{3}, p_{4}, p_{5}$. Then the logarithms of the odds (not the logarithms of the 158 probabilities) of answering in certain ways are: 


$$
\text { poor, } \log \frac{p_{1}}{p_{2}+p_{3}+p_{4}+p_{5}}, \quad 0
$$$$
\text { poor or fair, } \log \frac{p_{1}+p_{2}}{p_{3}+p_{4}+p_{5}}, \quad 1
$$

$$
\text { poor, fair, or good, } \log \frac{p_{1}+p_{2}+p_{3}}{p_{4}+p_{5}}, \quad 2
$$

poor, fair, good, or very good, $\log \frac{p_{1}+p_{2}+p_{3}+p_{4}}{p_{5}}, 3$

160 The proportional odds assumption is that the number added to each of these logarithms to get the 161 next is the same in every case. In other words, these logarithms form an arithmetic 162 sequence(McCullagh, 1980). The model states that the number in the last column of the table163 the number of times that that logarithm must be added - is some linear combination of the other 164 observed variables.

165 The coefficients in the linear combination cannot be consistently estimated using ordinary least 166 squares. They are usually estimated using maximum likelihood. The maximum-likelihood 167 estimates are computed by using iteratively reweighted least squares.

168 Examples of multiple ordered response categories include bond ratings, opinion surveys with 169 responses ranging from "strongly agree" to "strongly disagree," levels of state spending on 170 government programs (high, medium, or low), the level of insurance coverage chosen (none, 171 partial, or full), and employment status (not employed, employed part-time, or fully 172 employed)(McCullagh, 1980).

173 Suppose the underlying process to be characterized is

$$
y^{*}=\mathbf{x}^{\top} \beta+\varepsilon
$$


175 Where $\mathbf{y}^{*}$ is the exact but unobserved dependent variable (perhaps the exact level of agreement

176 with the statement proposed by the pollster); $\mathrm{X}^{\mathrm{T}}$ is the vector of independent variables, $\varepsilon$ is the

177 error term, and $\beta$ is the vector of regression coefficients which we wish to estimate. Further

178 suppose that while we cannot observe $\mathbf{y}^{*}$ we instead can only observe the categories of response

179

$$
y= \begin{cases}0 & \text { if } y^{*} \leq \mu_{1} \\ 1 & \text { if } \mu_{1}<y^{*} \leq \mu_{2} \\ 2 & \text { if } \mu_{2}<y^{*} \leq \mu_{3} \\ \vdots & \\ N & \text { if } \mu_{N}<y^{*}\end{cases}
$$

180 Where the parameters; $\boldsymbol{\mu}_{\mathrm{i}}$ are the externally imposed endpoints of the observable categories. Then 181 the ordered logit technique will use the observations on $y$, which are a form of censored data on $182 y^{*}$, to fit the parameter vector $\beta$.

183 In ordinal logistic regression model, there are two classifications namely binary and multinomial.

184 There are particular events when the scale of multiple category outcomes is not nominal but 185 ordinal. In such setting, one could use the multinomial logistic regression. This analysis however 186 would not take in to account the ordinal nature of the outcome and hence the estimated odds ratio 187 may not address the questions asked of the analysis (Hosmer \& Lemeshow, 2000b)

188 If an outcome variable $\boldsymbol{y}$ has $\boldsymbol{c}$ ordered categories $(c \geq 2)$, which we arbitrarily refer to as 189 $1, \ldots, c$.and also there are $\mathrm{k}$ covariates $x_{1},---, x_{k}$ an ordinal regression model is defined by

$$
\log \left[\frac{\operatorname{Pr}(y \leq j)}{\operatorname{Pr}(y \geq j+1)}\right]=\alpha_{j}+\beta_{1} x_{1}+\ldots+\beta_{k} x_{k}, \quad \text { Where } j=1---, c-1
$$

The regression coefficients $e^{\beta q}$ have a similar interpretation as for ordinary logistic regression. Specifically, 


$$
\begin{gathered}
e^{\beta q}=\frac{\left(\text { odds that } y \leq j \mid x_{q}=x\right)}{\text { odds } \left.\text { that } y \leq j \mid x_{q}=x-1\right)} \\
\boldsymbol{q}=\mathbf{1}, \ldots, \boldsymbol{k} \\
\boldsymbol{j}=\mathbf{2}, \ldots, \boldsymbol{k}
\end{gathered}
$$

Odds ratio for $y \leq j$ given $x_{q}=x v s x_{q}=x-1$ holding all other variables constant

190 If $c=2$, then the ordinal logistic regression model reduces to ordinary logistic regression. In

191 ordinal regression, $e^{\beta q}$ is assumed to be the same for each value. This type of ordinal regression

192 model is called a cumulative odds or proportional odds ordinal logistic regression model

193 (Rosner, 2010).

\section{Assumptions of logistic regression model}

195 Inferences drawn from statistical modeling are valid when key assumptions of the statistical 196 model are satisfied(Rosner, 2010). For the case of logistic regression analysis, the following 197 criteria are assumed to be satisfied.

198 1. Thedependent variable is measured on an ordinal level.

1992 2. One or more of the independent variables are either continuous, categorical or ordinal.

200 3. No Multi-collinearity - i.e. when two or more independent variables are highly 201 correlated with each other.

4. Proportional Odds- i.e. that each independent variable has an identical effect at each cumulative split of the ordinal dependent variable.

5. Logistic regression requires large sample sizes as compared to simple linear regression or multiple linear regressions.

Parallel Lines Assumption

207 In ordinal logistic regression models there is an important assumption which belongs to 208 ordinal odds. According to this assumption parameters should not change for different 209 categories. In other words, correlation between independent variable and dependent variable 210 does not change for dependent variable's categories; also parameter estimations do not change 
211 for cut-off points. In an ordinal logit regression, when the assumption holds for $j-1$ logit 212 comparison in a $\mathrm{J}$ categorized variable,,$\alpha_{J-1}$ cut- off points and $\beta_{J-1}$.parameters are

213 found. At this point ordinal logistic model differs from multinomial logistic regression.

214 Dependent variables which are analyzed in the majority of researches and applied studies are 215 generally in categorical and ordinal structure. Ordinal Logit Models that consider the ordinal 216 structure of the dependent variable are used in case where the dependent variable has at least 3 217 categories with these categories ordinally arranged, i.e. severe of disease (mild, moderate, 218 severe) or the educational level (elementary, high, university) (Hosmer \& Lemeshow, 2000a).

219 Ordinal logistic regression describes the relationships between an ordered response variables and 220 a set of predictor variables that can be continuous discrete, or a mixed of any of these. In ordinal 221 logistic regression analysis we have three types commonly used model: the Adjacent-category, 222 the continuation ratio and proportional odds models.

223 There are various ordinal logit models to compare dependent variable categories. Easiest of these 224 to apply or interpret are Cumulative Logit Models. Cumulative Logit Models are divided into 3 225 groups as Proportional Odds Model (POM), Non-Proportional Odds Model (NPOM) and Partial 226 Proportional Odds Model (PPOM). Not like the Multinomial Logit Models, Cumulative Logit 227 Models are work under the assumption of cumulative logitparallelity. But parallel lines 228 assumption sometimes does not hold, in this case Proportional Odds Model gives incorrect 229 results. Therefore models that consider ordinal structure and relax the assumption are suggested. 230 NPOM and PPOM are recently used for this purpose (Hosmer \& Lemeshow, 2000b).

\section{Cumulative Logit Models}

232 Various logit formats are used to compare dependent variable categories in ordinal logistic 233 models. But cumulative logits are the easiest models when it comes to interpret or apply. Like 
234 the other logit models, odds ratios are calculated to find cumulative probabilities in cumulative

235 logit models. There are $\mathrm{j}-1$ ways to compare $\mathrm{j}$ categorized dependent variable Y. Equality

236 shows odds ratio of dependent variable $\mathrm{Y}$ for $(\geq 1,<1 ; \geq 2,<2 ; \ldots \geq-1,<-1)$ (Kleinbaum \& Klein, 237 2010).

239 Results

240 Descriptive Statistics

241 The number of randomly selected accidents were 385, of which $56.7 \%$ of the injury was slight

242 injury, $28.6 \%$ were serious injury, $14.7 \%$ of the accidents were fatal injury. The distribution of 243 accident injury level by background characteristics are illustrated in Table 1 . In addition to the 244 distribution, the association between the injury level and associated factors also shown in Table 1 245 using the chi-square test of association. Years of experience, vehicle ownership (employed or 246 self), vehicle type, and vehicle owner (private or governmental) are found to be significantly 247 associated with the level of accident injury (Table 1).

248 Ordered Logistic Regression Analysis

249 This section focused on regression analysis undertaken to test the relative predictive power of 250 socio-demographic and environmental covariates with severity of car accident injury. In this 251 study ordinal logistic regression is selected for analyzing the car accident data using the 252 explanatory variables associated with the dependent variable. Accordingly, Age (Age of driver), 253 Educational Background of driver, Experience of driver, Service time of vehicle, type of accident 254 (crash with what object), Light condition during accident (day or night), Road pavement 255 (Asphalt, coble stone, aggregate), Road Partition (one way, two way), and vehicle type (bajaj, 256 taxi, heavy trucks, cross country bus) are included in the model. 
257 The log odds of fatal injury level for drivers with age group of 5-10 years age group is increased

258 by 0.686 . The estimated odds ratio $(\mathrm{OR}=1.986)$ indicates that the odds of fatal injury (as 259 opposed to moderate injury or slight injury) for older age drivers is $98.6 \%$ higher than young age 260 drivers (<5 years experience), as the odds of moderate or slight injury (as opposed to fatal 261 injury), holding other variables constant. The confidence interval for odds could be as minimum 262 as 1.002 and as maximum as 3.934 with $95 \%$ confidence and shows that it is statistically 263 significant as it doesn't include one. This result seems contradictory with the experience level, 264 but it could be due to the greater confidence of experienced drivers which may lead to carelessly 265 follow the ethics of driving like driving more than the allowed speed, not using seat belt and 266 talking mobile phone calls while driving.

267 The log odds of fatal injury for drivers who have privately own the vehicles is found to deceased 268 by 1.160 as compared to the vehicles owned by the government. The estimated odds ratio $(\mathrm{OR}=$ $2690 . .313$ ) shows that the odds of fatal injury (as opposed to moderate or slight injury) for drivers 270 who drive private owned vehicles is lower than those drivers who have drive governmental 271 vehicles is decreased by $68.7 \%$. The $95 \%$ confidence interval also suggests that odds could be as 272 minimum as 0.137 and as maximum as 0.714 .

273 The log odds of fatal injury for accident type; Vehicle with pedestrian is deceased by 2.852. The 274 estimated odds ratio $(\mathrm{OR}=0.058)$ shows that the odds of fatal injury (as opposed to moderate or 275 slight) for vehicle with pedestrian accident is lower than those accidents vehicle with vehicle by $27694.2 \%$. The 95\% confidence interval also suggests that odds could be as minimum as 0.031 and 277 as maximum as 0.106 .

278 The log odds of fatal injury for vehicle type; heavy track is deceased by 0.656 . The estimated 279 odds ratio $(\mathrm{OR}=0.519)$ shows that the odds of fatal injury (as opposed to moderate or slight) for 
280 heavy track accident is lower than those by automobile by $48.1 \%$. The $95 \%$ confidence interval

281 also suggests that odds could be as minimum as 0.263 and as maximum as 1.023 .

282 The log odds of fatal injury for vehicle type; cross country bus is deceased by 0.899 . The

283 estimated odds ratio $(\mathrm{OR}=0.411)$ shows that the odds of fatal injury (as opposed to moderate or

284 slight) for heavy track accident is lower than those by automobile by $58.9 \%$. The $95 \%$

285 confidence interval also suggests that odds could be as minimum as 0.189 and as maximum as

$286 \quad 0.894$

287 The log odds of fatal injury for vehicle owner; Vehicle owned driver is decreased by 2.852 .692

288 as compared to vehicle is owned by employer. The estimated odds ratio (OR $=0.502)$ shows that

289 the odds of fatal injury (as opposed to moderate or slight) for vehicle owned driver is lower than

290 those accidents with driver employed by $49.8 \%$ [Table 2].

\section{Discussion}

292 In this study, light condition is not found to be statistically significant (Coef. $=.145$; $p$-value $293>=0.050$ ); whereas according to (Huang, Chin, \& Haque, 2008) night time driving was 294 resulted a more serious injury outcome (Coef. $=0.3920$; $\mathrm{p}$-value $<=0.050$ ) than day time 295 driving. From vehicle type heavy truck (Coef. $=-.656$, p-value $>=0.050)$ and cross country 296 bus (Coef. $=-.889$, p-values $<=0.05$ ) were found to be statistically significantly decreasing 297 the severity of accident injury, which shows similar results with (Huang et al., 2008). The 298 time of accident was classified as day and night to indicate light and in this study; it was not 299 found statistically significant whereas studies conducted by (Huang et al., 2008; Simomcic, 2001) showed that accidents happened during the night increase the level of accident as compared to accident happened in the day time and the magnitude is similar with the result of 
this study regardless of its significance i.e. (Coef. $=.145 ; \mathrm{p}$-value $>=0.100)$. Vehicle type in this study is categorized as automobile, taxi, heavy truck, Cross country buss and Bajaj. The accidents occurred due to heavy truck and cross country buss were found to be decreasing the level of accident $($ Coef. $=-.656 ;$ p-value $<=0.050)$ and $($ Coef. $=-.889 ;$ p-value $<=0.050)$ respectively. This may be due to the drivers are highly skilled and experienced. Specially, for the heavy truck, since they are large in size and have at most two persons (the driver and his assistant) it is less likely to get a fatal injury. This is because they may skip of the accident by just jumping from the vehicle. This finding was supported by (Levine, Bedard, Molloy, \& Basilevsky, 1999) who found that every $454 \mathrm{~kg}$ increase in vehicle weight was equivalent to the driver's ability to resist front impact car accident of 10 more kph before being fatally injured.

\section{Limitations}

314 Since the data were not recorded primarily for this research purpose, there were important 315 variables missed in the format like use of seatbelt, alcohol use before accident, speed during 316 accident and speed limit of the place where accident happened.

\section{Conclusion}

An ordered logistic regression model was used to examine factors that worsen the car accident

319 level. A total sample of 385 car accidents were considered in the study of which $56.7 \%$ were 320 fatal, $28.6 \%$ serious and $14.7 \%$ slight injury. The model estimation result showed that, being 321 experienced drivers (Coef. $=0.686 ; \mathrm{p}$-value $<=0.050)$ were found to increase the level of injury.

322 On the other hand, being private vehicle (Coef. $=-1.160$; $\mathrm{p}$-value $<=0.010$ ), the type of accident 323 of vehicle with pedestrian (Coef. $=-2.852$; p-value $<=0.010)$, being heavy truck $($ Coef. $=-0.656$; 324 p-value $<=0.050$ ), being a cross country buss (Coef. $=-0.889$; p-value $<=0.050$ ) and being 
325 owner of vehicle is the driver himself (Coef. $=-.690, \mathrm{p}$-value $<=0.050$ ) were found to decrease 326 the level of car accident injury severity. Therefore, it is better to create continued awareness to 327 those who are experienced drivers, who carelessly follow the traffic rules. Special attention is 328 required to government owned vehicle drivers, as they were found to increase the level of car 329 accident injury through different short term trainings.

330 Generally, this study exerts an important effort to under-stand the effects of various 331 interdependent factors on car accident injury level. However, the study was forced to be limited 332 to show variation in the interaction of factors across different scenario of collision due to the 333 small sample, because the data were not in softcopy rather in hard copy. Therefore, it was very 334 difficult to consider more samples in this situation. So, we recommend the traffic police office of 335 Mekelle city to develop a data base on car accident in order to investigate more results using 336 different statistical models.

337 Based on these findings some interventions can be developed to minimize the level of cara 338 accident in Mekelle City, Ethiopia. Prevention strategies applied to reduce injuries and fatalities 339 from car accident should focus on continued awareness creation to experienced drivers, 340 government employed driver on speeding, and driving at night time. Therefore, implementing 341 better driver licensing and road safety awareness campaign on safe driving practices can play a 342 pivotal role in road safety improvement. In addition, strict police enforcement also applied for 343 those frequent offenders. Most importantly, it is needed to prepare a huge data base that includes 344 driver alcohol used or not, road characteristics at time of accident, road speed limit for further 345 investigation. 
Not applicable

349 Declarations

350

351 Ethics approval and consent to participate

352 The office of research and community services of Mekelle University, College of Natural and

353 Computational Sciences approved the study protocol. Any personal name was not encoded;

354 identifiers of the injured individuals were simply serial numbers.

\section{Consent for publication}

356 Not applicable

\section{Availability of data and material}

359 The data is found in hard copy at the College of Health Science Main Library and in soft copy at 360 the university research and community service office website.

\section{Competing interests}

363 All the authors declare that they have no competing interests.

\section{Funding}

This study was funded by Mekelle University, Ethiopia (Grant number:

RPO/CNCS/SM/011/09). The funding organization has no role in the manuscript except funding.

\section{Authors' contributions}

HGM; designed the study, analyzed the data using STATA software and drafted the manuscript

370 and incorporated the comments from co-authors.

371 DBG, FG, GGW and TG; they critically commented and reviewed starting from the design up to

372 the final manuscript. All authors read and approved the final manuscript.

373 
Acknowledgements

We are grateful to the management bodies and traffic police officers of Mekelle city involved in the data collection process. We thank Mekelle University research and community Service office for funding the research for collection and analysis of the data.

\section{References}

Al-Ghamdi, A. S. (2002). Using logistic regression to estimate the influence of accident factors on accident severity. Accident Analysis \& Prevention, 34(6), 729-741.

Goswami, A., \& Sonowal, R. (2009). A statistical analysis of road traffic accidents in Dibrugarh City, Assam, India. Division of Epidemiology and Nutrition, Regional Medical Research Centre.

Hosmer, D. W., \& Lemeshow, S. (2000a). Interpretation of the fitted logistic regression model. Applied Logistic Regression, Second Edition, 47-90.

Hosmer, D. W., \& Lemeshow, S. (2000b). Special topics: Wiley Online Library.

Huang, H., Chin, H. C., \& Haque, M. M. (2008). Severity of driver injury and vehicle damage in traffic crashes at intersections: a Bayesian hierarchical analysis. Accident Analysis \& Prevention, 40(1), 45-54.

Kleinbaum, D. G., \& Klein, M. (2010). Introduction to logistic regression Logistic regression (pp. 1-39): Springer.

Levine, E., Bedard, M., Molloy, D., \& Basilevsky, A. (1999). Determinants of driver fatality risk in front impact fixed object collisions. Mature Medicine Canada, 2, 239-243.

McCullagh, P. (1980). Regression models for ordinal data. Journal of the royal statistical society. Series B (Methodological), 109-142.

Odero, W., \& Ayuku, D. (2003). Violence and alcohol: a study of injury presentations to Emergency Departments in Eldoret, Kenya: short research report. African safety promotion, 1(2), 38-42.

Organization, W. H. (2009). Global status report on road safety: time for action: World Health Organization.

Peden, M., Scurfield, R., Sleet, D., Mohan, D., Hyder, A. A., Jarawan, E., \& Mathers, C. D. (2004). World report on road traffic injury prevention: World Health Organization Geneva.

Rallis, T. (1977). INTERCITY TRANSPORT. ENGINEERING AND PLANNING.

Rosner, B. (2010). Fundamentals of Biostatistics. Cengage Learning. Inc., Kentucky.

Simomcic, M. (2001). Road accident in Slovenia involving a pedestrian, cyclist or motorcyclist anda a car. Accident Analysis and Prevention, 33, 147-156.

WHO, W. (2013). Global status report on road safety 2013: supporting a decade of action: World Health Organization Geneva. 
418 Table1: Distribution of vehicles' accident injury level from September 2014 -August 2017

\begin{tabular}{|c|c|c|c|c|c|c|}
\hline \multirow[t]{3}{*}{ Variable } & \multirow[t]{3}{*}{ Categories } & \multicolumn{5}{|c|}{ Accident Injury Level Frequencies } \\
\hline & & Fatal Injury & Serious Injury & Slight Injury & Total & \\
\hline & & $216(56.7 \%)$ & $109(28.6 \%)$ & $56(14.7 \%)$ & $385(100 \%)$ & $\mathrm{P}$-value $<=$ \\
\hline \multirow[t]{4}{*}{ Driver's age } & $<25$ years & $16(17.58 \%)$ & $42(46.15)$ & $33(36.26)$ & $91(100 \%)$ & $0.001 * * *$ \\
\hline & $25-45$ years & $35(13.67 \%)$ & $55(21.48 \%)$ & $166(64.84 \%)$ & $256(100 \%)$ & \\
\hline & 46-65 Years & $4(12.90 \%)$ & $11(35.48)$ & $16(51.61 \%)$ & $31(100 \%)$ & \\
\hline & $65+$ & $2(28.57 \%)$ & $1(14.28 \%)$ & $4(57.14)$ & $7(100 \%)$ & \\
\hline Driver's & $<5$ years & $36(16.14 \%)$ & $72(32.29 \%)$ & $115(51.57 \%)$ & $223(100 \%)$ & 0.229 \\
\hline \multirow[t]{2}{*}{ Experience } & $50-10$ years & $8(10.53 \%)$ & $16(21.05 \%)$ & $52(68.42 \%)$ & $76(100 \%)$ & \\
\hline & $>10$ years & $12(14.63 \%)$ & $21(25.61 \%)$ & $49(59.76 \%)$ & $82(100 \%)$ & \\
\hline \multirow[t]{2}{*}{ ownership } & Employed & $45(13.68 \%)$ & $82(24.92 \%)$ & $202(61.40 \%)$ & $329(100 \%)$ & $0.001 * * *$ \\
\hline & Own(self) & $11(21.15 \%)$ & $27(51.92)$ & $14(26.92)$ & $52(100 \%)$ & \\
\hline \multirow[t]{5}{*}{ Vehicle Type } & Automobile & $16(10.88 \%)$ & $35(23.81 \%)$ & $96(65.31 \%)$ & $147(100 \%)$ & $0.001 * * *$ \\
\hline & Heavy Tracks & $13(16.25)$ & $15(18.75 \%)$ & $52(65.00 \%)$ & $80(100 \%)$ & \\
\hline & Taxi & $2(5.56 \%)$ & $17(47.22 \%)$ & $17(47.22 \%)$ & $36(100 \%)$ & \\
\hline & Bajaj & $11(24.44)$ & $21(46.67 \%)$ & $13(28.89 \%)$ & $45(100 \%)$ & \\
\hline & Bus & $9(16.98 \%)$ & $12(22.64 \%)$ & $32(60.38 \%)$ & $53(100 \%)$ & \\
\hline \multirow[t]{2}{*}{ Ownership type } & Government & $2(3.33 \%)$ & $11(18.33 \%)$ & $47(78.33)$ & $60(100 \%)$ & $0.001 * * *$ \\
\hline & private & $54(16.62 \%)$ & $98(30.53 \%)$ & $169(52.65)$ & $321(100 \%)$ & \\
\hline \multirow[t]{2}{*}{ Road partition } & One way & $9(10.00 \%)$ & $27(30.00 \%)$ & $54(60.00 \%)$ & $90(100 \%)$ & 0.381 \\
\hline & Two way & $47(16.15 \%)$ & $82(28.18 \%)$ & $162(55.67 \%)$ & $291(100 \%)$ & \\
\hline \multirow[t]{2}{*}{ Road Condition } & Dry & $55(14.55 \%)$ & $108(28.57 \%)$ & $215(56.88 \%)$ & $378(100 \%)$ & 0.598 \\
\hline & Wet & $2(28.57 \%)$ & $3(48.86 \%)$ & $2(28.57 \%)$ & $7(100 \%)$ & \\
\hline \multirow[t]{2}{*}{ Light } & Day & $42(14.29 \%)$ & $76(25.86 \%)$ & $176(59.86 \%)$ & $294(100 \%)$ & 0.053 \\
\hline & Night & $14(16.09 \%)$ & $33(37.93 \%)$ & $44(448.35 \%)$ & $91(100 \%)$ & \\
\hline \multirow[t]{3}{*}{ Accident Type } & Vehicle-Vehicle & $11(5.67 \%)$ & $36(18.56 \%)$ & $147(75.77 \%)$ & $194(100 \%)$ & $0.001 * * *$ \\
\hline & Vehicle-Other & $6(9.09 \%)$ & $6(9.09 \%)$ & $54(81.82 \%)$ & $66(100 \%)$ & \\
\hline & Vehicle-Pedestrian & $39(32.77 \%)$ & $67(56.30 \%)$ & $13(10.92 \%)$ & $119(100 \%)$ & \\
\hline
\end{tabular}

419 Note: ${ }^{* * *}=$ significant at $1 \%$ level of significance 
426 Table 2: Factors affecting Car Accident Injury Level: Ordered Logistic Regression result.

\begin{tabular}{|c|c|c|c|c|c|c|}
\hline Variables & Category & Coefficient & $\begin{array}{l}\text { Odds } \\
\text { ratio }\end{array}$ & $\begin{array}{l}\text { Stand. } \\
\text { error }\end{array}$ & z-value & P-value $<=$ \\
\hline \multirow[t]{4}{*}{ Driver's Age } & $<25$ years (ref) & & & & & \\
\hline & 25-45 years & .437 & 1.548 & .318 & 1.37 & 0.170 \\
\hline & 46-65 Years & -.104 & .901 & .530 & -0.20 & 0.844 \\
\hline & $65+$ & 11.555 & 104329.3 & 714.387 & 0.02 & 0.987 \\
\hline Driver's & $<5$ years (ref) & & & & & \\
\hline \multirow[t]{2}{*}{ Experience } & $5-10$ years & .686 & 1.986 & .349 & 1.97 & $0.049 * *$ \\
\hline & $>10$ years & .249 & 1.283 & .357 & 0.70 & 0.485 \\
\hline Vehicle service & Vehicle service & -.001 & .999 & .002 & -0.61 & 0.542 \\
\hline \multirow[t]{2}{*}{$\begin{array}{l}\text { Ownership } \\
\text { type }\end{array}$} & $\begin{array}{l}\text { Governmental } \\
\text { (ref) }\end{array}$ & & & & & \\
\hline & Private & -1.160 & .313 & .420 & -2.76 & $0.001 * * *$ \\
\hline \multirow[t]{2}{*}{ Light condition } & Day (ref) & & & & & \\
\hline & Night & .145 & 1.556 & .305 & 0.48 & 0.634 \\
\hline \multirow[t]{3}{*}{ Accident type } & $\begin{array}{l}\text { Vehicle-Vehicle } \\
\text { (ref) }\end{array}$ & & & & & \\
\hline & Vehicle-Other & .408 & 1.503 & .413 & 0.99 & 0.323 \\
\hline & $\begin{array}{l}\text { Vehicle- } \\
\text { pedestrian }\end{array}$ & -2.852 & .058 & .317 & -8.98 & $0.001 * * *$ \\
\hline \multirow[t]{5}{*}{ Vehicle Type } & Automobile (ref) & & & & & \\
\hline & Heavy track & -.656 & .519 & .346 & -1.89 & $0.050 * *$ \\
\hline & Taxi & .303 & 1.354 & .439 & 0.69 & 0.491 \\
\hline & Bajaj & -.115 & .892 & .420 & -0.27 & 0.785 \\
\hline & Cross country bus & -.889 & .411 & .396 & -2.24 & $0.025 * *$ \\
\hline \multirow[t]{2}{*}{ Vehicle owner } & My employer (ref) & & & & & \\
\hline & My self & -.690 & .502 & .373 & -1.85 & $0.044 * *$ \\
\hline
\end{tabular}




\begin{tabular}{llll}
\hline /cut1 & & -6.056 & 1.009 \\
/cut2 & -3.792401 & .966 \\
Model & Number of obs. & 344 & \\
Summary & Log likelihood & -244.113 & \\
& LR chi2(15) & 162.82 & \\
& Prob > chi2 & 0.0000 & \\
& Pseudo R2 & 0.2501 & \\
& &
\end{tabular}

427 Note: $* * *=$ significant at $1 \%, * *=$ significant at $5 \%$

428

429

430

431

432

433

434 Author details

$435{ }^{1}$ Department of Biostatistics, School of Public Health, College of Health Sciences, Mekelle

436 University, Ethiopia

$437{ }^{2}$ Department of Economics, College of Business and Economics, Mekelle University, Ethiopia

$438{ }^{3}$ Department of Nutrition and dietetics, School of Public Health, College of Health Sciences,

439 Mekelle University, Ethiopia

$440{ }^{4}$ Deparment of Statistics, College of Natural and Computational Sciences, Mekelle University,

441 Ethiopia

442

443

444

445

446

447

448

449

450

451

452 
453

454

455

456

457

458

459

460

21 P a g e 


\section{Supplementary Files}

This is a list of supplementary files associated with this preprint. Click to download.

- STROBEchecklistcrosssectional.doc 